\title{
Mechatronic Design for A new Incremental Launching System and Its Application of Launching Variable Cross-section Girder in Urban
}

\author{
Hong Zhang ${ }^{1}$, Xiaoping Zhang ${ }^{2, *}$ and Mengyuan Zhang ${ }^{2}$ \\ ${ }^{1}$ CCCC Second Harbor Engineering Company Ltd., 430040, China \\ ${ }^{2}$ CCCC Wuhan Harbor Engineering Design and Research Company Ltd., 430040, China \\ ${ }^{*}$ Corresponding author
}

\begin{abstract}
This paper mainly introduced the machatronic design of the 70Mpa 1600 tonne Incremental Launching system. Firstly, the 6 Degrees of Freedom adaptive mechanical launching device and its hydaulic system were described. Then, in order to properly statisfy the requirments of the launching function during construction in practice, a distributed sensing and control systems were corresponding established. In addition, modular integration method was adopted to rapid establish the incremental launching system, closed-loop iterative control algorithm was remotely applied to garentee the synchronization and safty performance of distributed on-site devices. In terms of using this system, Dongfeng Avenue freeway $\mathrm{L} 7 \mathrm{89m}$ viaduct was successfully launched. Finally, the proposed design of ILS was discussed and concluded.
\end{abstract}

Keywords-incremental launching; bridge girder; synchronous launching movements; construction bridge shape

\section{INTRODUCTION}

Due to the excellence on device integration, high bearing capacity and excellent implementation of construction compare to bracket erecting and dragging-type launching method [1-7], the incremental launching method is widely used to construct various kinds of bridges in urban, canyon, the regions across rivers and offshore where traffic, geology and topography conditions are limited [8-10]. By using IL method, the bridge girder with a temporary guiding nose [11] is capable of being assembled on one side of the obstacle and launched direct to the other side without previous constructing a large number of temporary supports or using large-scale hoisting devices.

There are numerous construction projects involved with launching method. The most representative application was the construction of Millau viaduct [12-14], as shown in Figure I, the girder of which is launched in terms of a wedge-type launching system. The mechanical structure of WL device mainly includes a pair of high precision wedge blocks. The bridge girder is launched through a lifting-pushing coupled motion achieved by the sliding between wedges. Driven by the remote control hydraulic system, the multiple on-site WL devices provides a much better synchronous launching motions in the vertical plane and more moderate horizontal tractions [15] to the temporary supporters when compares to using dragging-type launching devices. However, the precision and durability of coupled launching motions, to a large extent, are depend on the dimension quality of the wedge blocks and the motion control of the sliding kinematics. The wedge blocks and the control system are designed to be very accurate and complex so that design and maintenance cost are considerably high. Meanwhile, the sliding motions at multiple launching stations is not capable of providing the adaption to the launching adjustment in horizontal plane and to the curve features of the launching interface. Further, the on-site WL device has a quite large structure dimension that demands larger and stiffer piers and is not suitable for the launching construction in urban where space is limited.

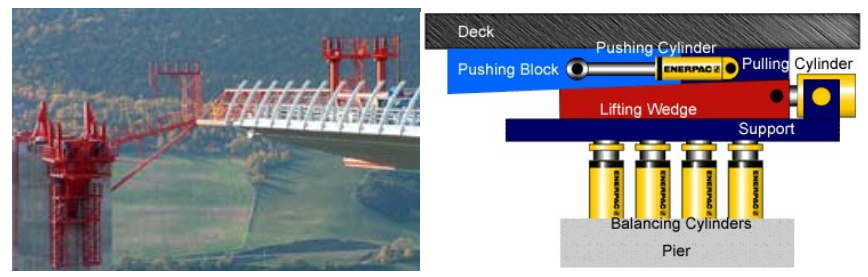

FIGURE I. THE CONSTRUCTION SITE OF MILLAU VIADUCT AND WEDGE-TYPE LAUNCHING SYSTEM

To simplify the design and lower the overall costs of the launching system, a walking-type launching device [16-17] is developed and successfully applied in the construction of Jiubao bridge, which is a three-span beam-arch composite bridge across the Qiantang river with the length of $1855 \mathrm{~m}$. Up to $20 \mathrm{IL}$ devices are used to complete the launching construction, the total weight of $14 \mathrm{k}$ tonne. The IL device is designed to have the independent motions function that is capable of launching the bridge girder in Cartesian space without coupled mechanisms or complicated hydraulic transmission systems. The launching motions are decomposed as lifting, pushing, dropping and returning. The IL devices are serially assembled on the working space of every $\mathrm{V}$-shape pier and are integrated with the communication bus, the embedded control unit, and the local hydraulic systems. With the help of control strategy of "displacement synchronization, load tracking", the synchronicity of multi-point launching is guaranteed. This IL system are widely used in many other launching project, such as the constructions of Luozhou bridge, RuanJiangxi bridge, Erqi Yangzi bridge and etc. in China. Still, the structure dimension of this IL device is comparably large 
when confronted with the launching construction in urban. To a large extent, the adaption to the geometric features of the bridge girder is still affected by its large structure dimension, as well. Although the difficulties of fine controlling the synchronicity of multi-point launching is largely reduced by introducing the embedded control units, the overall cost of maintenance is relatively high for its special design and formulation.

In the remaining part of the paper, we introduced a newly designed IL system that is very suitable for the launching construction [18] of variable cross section bridge girder. With the 6-DoF launching motion ability and 70Mpa launching pressure, the mechanical structure of the new IL device is designed to be compact enough to fully adapt to the curve features of the launching interface with considerable bearing capacity. The hydaulic systems and control systems are modularly designed that the failure rate and the cost of mainenance are apperently reduced. By cooperating the selfadptive control algorithm with the automatic launching strategy in the Dongfeng Avenue freeway L7 89m viaduct launching project, the accuracy of the construction bridge shape and the launching synchronicity is well controlled within the tolerance.

\section{INCREMENTAL LAUCNHING METHOD AND DEVICES}

The incremental launching device is the tool for launching construction. Often, the bridge girder is launched by means of using multiple pairs of them on the pies or temporary pies. The construction sequence of incremental launching includes 4 steps, which are lifting up, pushing forward, lowering down and resetting.
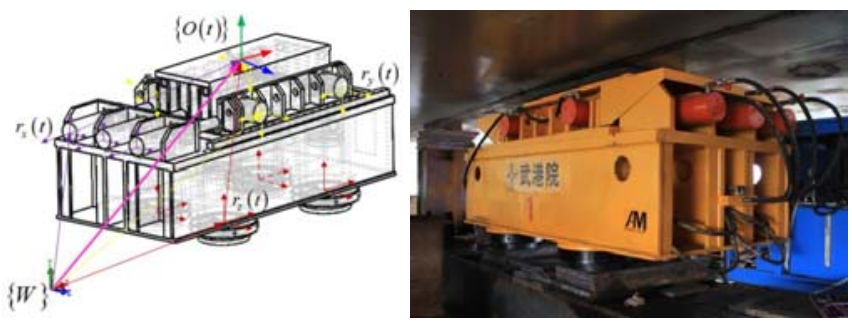

FIGURE II. HE CONSTRUCTION SITE OF MILLAU VIADUCT AND WEDGE-TYPE LAUNCHING SYSTEM

When the IL devices are ready to launch the bridge girder, the launching interfaces are simultaneously contact with the bottom surface of the girder with proper preload. Then, the lifting jacks of each IL device are pulling upwards so that the girder is detached from the supporters until the launching height reaches the designed value. After that, the pulling jacks stretch out, along with the girder in terms of the static friction of each contact. When launching distance within every launching sequence is reached, the lifting jacks pull back to its lifting zero position, during which the girder lowers down until detaching with every IL devices and sustained by supporters or temporary pies. Finally, the pulling jacks retracted, and the IL devices pull back to their pushing zero positions and ready for the next iterated launching sequence. To note that, the launching construction of bridge girder needs intermittent transverse adjustment due to construction uncertainties like generation of sliding friction during launching, or curve features of girder itself in horizontal plane.

In order to properly statisfy the requirments of the launching movements during each iteration of construction sequence, the launching device itself needs corresponding carrying capacity and flexible movement coordination. Thus, as shown in Figure II, the mechanical structure of IL device is designed as a $2.43 \mathrm{~m}^{*} 1.1 \mathrm{~m} * 1.11 \mathrm{~m}$ bearing case, on which two orthogonal sliding layers are assembled. The bearing structure is supported by 4 lifting jacks of maximum lifting force $4 * 4000 \mathrm{KN}$ with the stroke of $300 \mathrm{~mm}$. The lifting jacks are spherically hinged so that IL device is capable of local vertical moving and 3-dimensional angular fine tuning which are in the directions of linear $\mathrm{z}$ and angular $\mathrm{x}, \mathrm{y}, \mathrm{z}$. The IL device can easily adapted to the complex curve feature of bottom surface of the girder by controlling the lifting heights of each jacks. The middle sliding layer is connected to 3 parralled pushing jacks of maximum $3 * 500 \mathrm{KN}$ with the stroke of $350 \mathrm{~mm}$. When pushing the bridge girder in direction $\mathrm{x}, 3$ jacks strech out together. While, only the middle jack works when IL device is resetting. The top sliding layer's indepenent movement which is generated by 4 single-acting jacks of maximum $2 * 750 \mathrm{KN}$ pushing force with the stroke of $6 \mathrm{~mm}$, is designed in order to adjust the bridge girder's position in transverse y direction.

There are PTFE material between layers' surfaces to reduce the steel to steel frictional effects for the pushing, resetting and adjusting movement. Meanwhile, there is a cusion layer install on the top of the layer as the contact media to ensure the surface contact is generated between the bridge girder and IL devices.

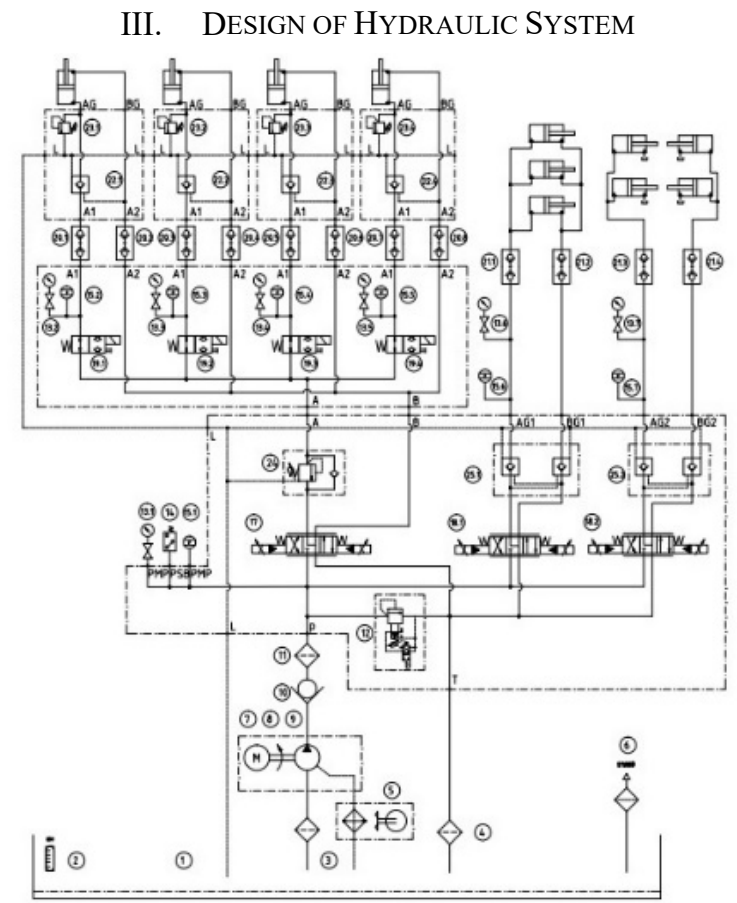

FIGURE III. THE HYDRAULIC DESIGN FOR THE INCREMENTAL LAUNCHING SYSTEM 
To fulfill IL device's movements during launching sequence, the specified hydraulic system is designed to provide the power for the IL devices, as shown in Figure III. The system mainly includes a quantitative plunger pumping with $15 \mathrm{KW}$ frequency motor to provide maximum $70 \mathrm{Mpa}$ pressure with the flow rate of $12 \mathrm{~L} / \mathrm{min}$, or to provide $31.5 \mathrm{Mpa}$ pressure with the flow rate of $23 \mathrm{~L} / \mathrm{min}$ for light duty construction condition. 3 proportional direction values are adopted for fine tuning the flow rate of lifting jacks, pushing jacks and adjusting jacks, respectively. In term of using closelooped PID control algorithm and multi-point synchronous launching strategy, the launching movement's synchronization accuracy of all IL devices are guaranteed. Other components such as relief valves, balancing valves, one-way valve, safety valves are modular selected to prevent system pressure overload or pressure loss, and to maintain the system pressure, etc.

4 lifting jacks are paralleled connected to the proportional direction value so that the lifting pressures of all cylinders are well balanced. The 3 pushing jacks and 4 adjusting jacks are configured in the same manner to make sure the reliability and stability of overall launching process.

\section{INTEGRATION OF CONTROL AND SENSING SYSTEM}

During each iterated launching sequence, there are often even number IL devices performing synchronized actions. To a large extent, the accuracy of the synchronized movements of all IL devices decides the safety and efficiency of the construction. Therefore, a distributed automation control system is designed, shown in Figure VI, which is based on the mechanical functions of launching movements and its characteristic of hydraulic transmission.

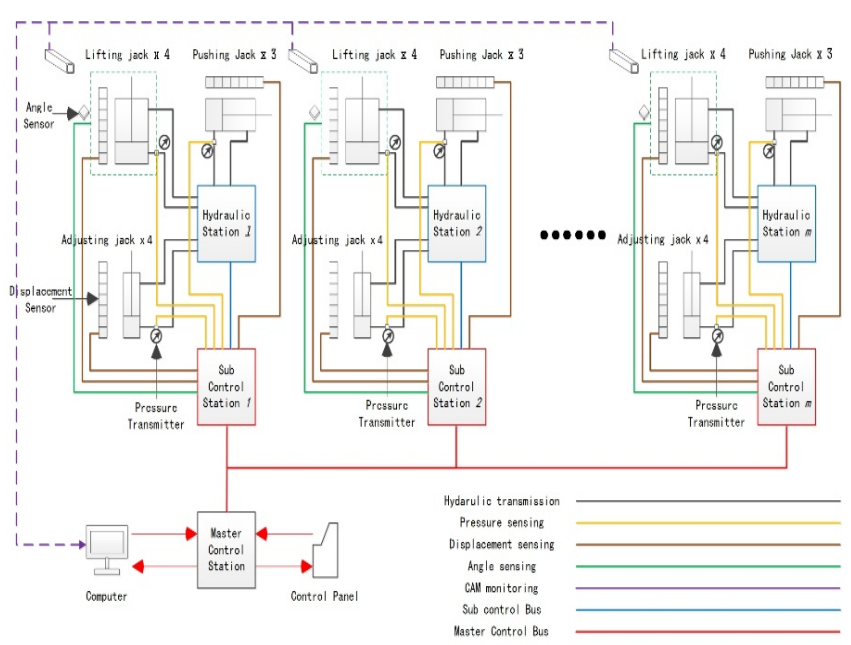

FIGURE III. THE LAYOUT DESIGN OF DISTRIBUTED CONTROLLING AND SENSING SYSTEM

The hardware platform of the control system is established in terms of ProfiBus-DP distributed PLC control system, which mainly is consist of a Simens S7-300 PLC module based mater control unit and multiple Simens S7-200 PLC module based on-site sub control units.

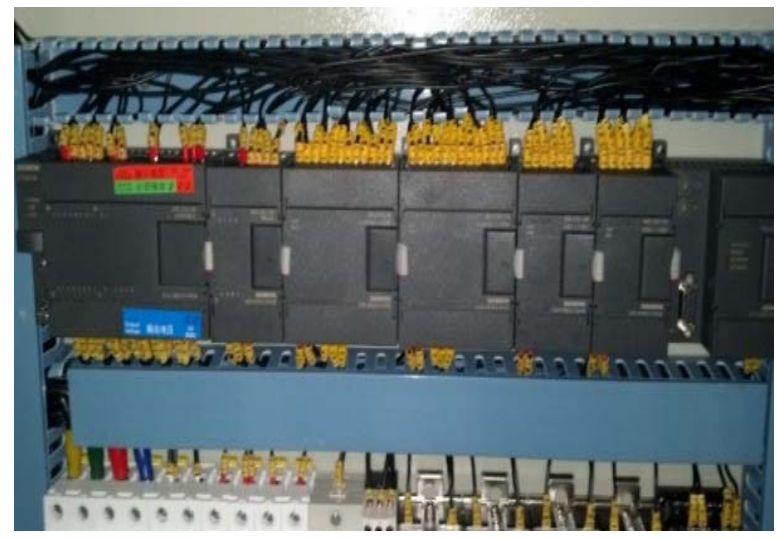

FIGURE IV. THE LAYOUT DESIGN OF DISTRIBUTED CONTROLLING AND SENSING SYSTEM

As shown in Figure $\mathrm{V}$, the sub control unit is assembled by S7-200 CPU module with 14 digital inputs (DI) and 10 digital outputs (DO), EM-222 module with 8 DO, 2 EM-235 analog inputs (AI) modules, 2 EM-232 analog outputs (AO) modules and EM-222 ProfiBus communication module, sequentially. Together with CPU module, the input and output modules are designed to receive the signals from on-site displacement sensors, pressure sensors, angular sensors and control commands from master control unit such as start/stop of pump, lifting/pushing/adjusting of launching movements, switching of relay contactor, etc. the brief functional inputs and outputs are list as follows in TABLE I.

TABLE I. THE INPUTS/OUTPUTS AND CORRESPONDING FUNCTIONS

\begin{tabular}{|c|c|c|c|c|c|}
\hline Inputs & Var. & Outputs & Var. & Ports & Var. \\
\hline I0.0 & pump start & Q0.0 & KM1 & AIW0 & $\begin{array}{l}\text { lifting } \\
\text { pos. } 1\end{array}$ \\
\hline I0.1 & pump stop & Q0.1 & KM2 & AIW2 & $\begin{array}{l}\text { lifting } \\
\text { pos. } 2\end{array}$ \\
\hline I0.2 & lift & Q0.2 & KM3 & AIW4 & $\begin{array}{l}\text { lifting } \\
\text { pos.3 }\end{array}$ \\
\hline I0.3 & descend & Q0.3 & $\begin{array}{l}\text { press. } \\
\text { built }\end{array}$ & AIW6 & $\begin{array}{l}\text { lifting } \\
\text { pos. } 4\end{array}$ \\
\hline I0.4 & push & Q0.4 & alarm & AIW8 & $\begin{array}{l}\text { pushing } \\
\text { pos. }\end{array}$ \\
\hline I0.5 & reset & Q2.0 & $\begin{array}{c}\text { lift jack } \\
1\end{array}$ & AIW10 & $\begin{array}{l}\text { adjusting } \\
\text { pos. }\end{array}$ \\
\hline I0.6 & adjust (left) & Q2.1 & $\begin{array}{c}\text { lift jack } \\
2\end{array}$ & AIW12 & $\begin{array}{l}\text { pump } \\
\text { press. }\end{array}$ \\
\hline I0.7 & adjust(right) & Q2.2 & $\begin{array}{c}\text { lift jack } \\
3\end{array}$ & AIW14 & angles \\
\hline I1.0 & manual & Q2.3 & $\begin{array}{c}\text { lift jack } \\
4\end{array}$ & AQW0 & lift coil \\
\hline I1.1 & press. built & & & AQW4 & $\begin{array}{l}\text { descend } \\
\text { coil }\end{array}$ \\
\hline I1.2 & motor on & & & AQW8 & $\begin{array}{c}\text { pushing } \\
\text { coil }\end{array}$ \\
\hline I1.3 & motor malf. & & & AQW10 & $\begin{array}{l}\text { pulling } \\
\text { coil }\end{array}$ \\
\hline I1.4 & $\begin{array}{l}\text { phase seq. } \\
\text { fail. }\end{array}$ & & & AQW12 & $\begin{array}{c}\text { adjust coil } \\
1\end{array}$ \\
\hline I1.5 & emerg. stop & & & AQW14 & $\begin{array}{c}\text { adjust coil } \\
2\end{array}$ \\
\hline
\end{tabular}


The start/stop conditions of the hydraulic pump is triggered by the 3-way knob switch, and the motor is started in terms of star-triangle startup mode.

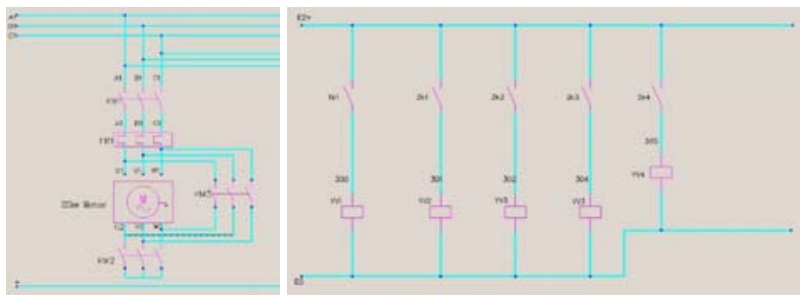

FIGURE V. THE ELECTRICAL CIRCUITS OF 22KW MOTOR

As shown in Figure VI, there are 3 contactors in the electrical circuits. In the main circuit, KM1 is configured as the Schneider LE1D50, the current capacity of which is 50A with the maximum power of $22 \mathrm{KW}$. KM2 works as the star contactor, which is configured as the Schneider LC1D25 with a maximum $25 \mathrm{~A}$ current capacity and $11 \mathrm{KW}$ power. KM3 works as the triangle contactor, which is capable of carrying a maximum $38 \mathrm{~A}$ phase current with $18.5 \mathrm{KW}$ power. When the knob pointer is at pump start position, KM1 and KM2 are connected. KM3 is connected and KM2 is disconnected 5 seconds later, the delay of which is set by the Timer T33. Then, the motor is in normal operation condition and is self-locking till the knob pointer is at stop position. When emergency happens, the emergency button is pressed and the motor stops until alarm command is reset. Further, KM2 and KM3 are designed to interlock each other to prevent the shorting out.

To establish the pump pressure, relay $1 \mathrm{~K} 1$ is designed. Its normal-open status is send to input I1.1 and output Q0.1 as the automation control command. The status of I0.1 to I0.7 are the control commands of lifting, pushing, pulling, adjusting left, adjusting right, respectively. There are 3 switches are configured as the 3-way twisted switch to trigger the corresponding movement of launching. For instance, when the pointer of lifting switch is at upper position, I0.1 is on so that lifting movement is executed. While, the pointer is at lower position, I0.2 is on so that descending movement is executed. When the pointer is at default position, I0.1 and I0.2 are off so that no lifting movement is executed.

The conversion of launching movements and synchronicity of multiple IL devices are guaranteed in terms of the fine controlling the proportional multi-way direction valve. The opening stroke of the value is linear changed with the 0500MA drive current, which is controlled by the analog signals from EM-235 ports AQW0, AQW4, AQW8, AQW10, AQW12, AQW14 with 0 to 20MA current signal. The controlling current is amplified to the drive current by means of using a proportional valve amplifier, which is assorted assembled within the hydraulic station.

When the motor malfunctions, I1.3 is on and thermal relay disconnects. The phase sequence relay encounters failure, while I1.4 is on. Otherwise, in the normal condition, coil contactors 16 and 25 are disconnected, coil contactor 18 and 28 are connected. In the case of lacking of certain phase sequence, the corresponding coil will lose power and coil connectors 16 and 26 are connected which lead to the stop of the PLC and condition ON of the fault indicator light.

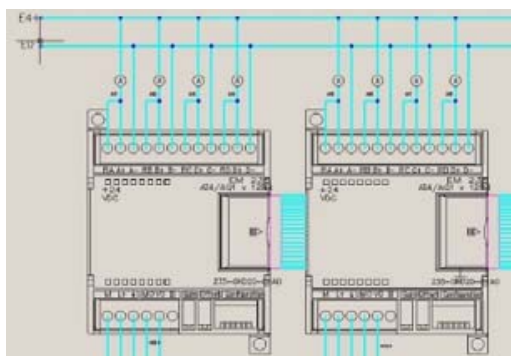

\section{FIGURE VI. THE ELECTRICAL CONNECTIONS AMONG EM-235} MODULE AND SENSING SIGNALS

In order to setup the close-loop control system, several sensors are assembled on the on-site IL devices to measure the displacements of all launching jacks, the pressure of the hydraulic systems, and the slant angles of launching interfaces. Draw-wire displacement sensors are used due to its characteristics of convenient installation and maintenance and are configured as the Milang $500 \mathrm{~mm}$ and $300 \mathrm{~mm}$ measuring range displacement sensors with accuracy of $0.1 \% \mathrm{FS}$. The angle sensor is configured as the Shuofeng 45 degree biaxial angle sensor with accuracy of 0.1 degree. To monitor the pressure, pressure transmitters are assembled both on the main circuit and sub-circuits of the hydraulic system. The format of the signals are analog 4-20MA current, which is received by the EM-235 module. The electrical connections are described in Figure VII. Further, the analog signals are transformed into 0-32000 digital value and stored in the AIW sections.

As shown in Figure VIII, the remote master control units are configured as the Simens S7-313C-2 DP CPU module and an extended DI16/DO16 module. The main functions of the master control system is to receive the sensing signals sent from the sub control systems which are connected by means of using the ProfiBus-DP. In addition, the master control unit connects to the computer through a MPI/USB cable to send and fetch status signals to the computer for analyzing and controlling the accuracy of the construction curve of bridge girder and synchronous launching movements of all IL devices in terms of construction bridge shape control strategy and selftuning PID iterative algorithm, which are depicted in Figure VIIII. The master control units and the computer are integrated in the IP45 control case which is onboard with all launching functional buttons and switches for remote controlling and fine tuning the launching construction.

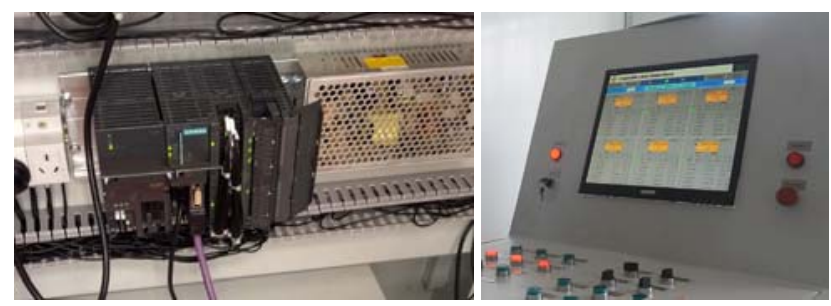

FIGURE VII. THE MASTER CONTROL UNIT AND REMOTE CONTROL STATION 

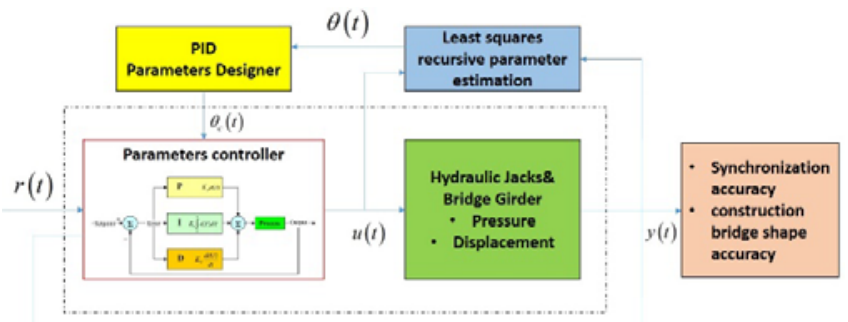

\section{FIGURE VIII. THE ADAPTIVE PID CONTROL ALGORITHM}

Further, considering the characteristics of the launching construction, ProfiBus-DP is adopted for the integration of the control and sensing systems, which connects multiple distributed on-site sub units together with the remote master control unit. The Profibus-DP cable is a twisted-pair cable, which provides the transmission rate at $500 \mathrm{Kbps}$ when the overall distance of sub units is $400 \mathrm{~m}$, or at $1500 \mathrm{Kbps}$ when the distance is shorten to $100 \mathrm{~m}$. Its transmission features provide a very good communication platform for the remote control of multi-launching construction, the maximum number of sub units is 127 , and the maximum distance is $1000 \mathrm{~m}$, which is especially suitable for the small and medium span urban bridge launching construction. In addition, standardization of its electrical interfaces make the fast integration possible. Based on the specifications of mechanical structures and hydraulic system, these control units is capable of flexibly adjusting the $\mathrm{I} / \mathrm{O}$ design and temporarily combining the extended units, using which bring increase of launching efficiency and reduction of maintenance cost.

\section{APPliCATION OF LAUNCHING CONSTRUCTION IN PRACTICE}

Dongfeng Avenue freeway viaduct is a typical continuous composite beam-steel bridge started from Wangjiazui overpass bridge to Wuhan belt expressway in Wuhan urban, P.R. China, the total span of which is $5,808 \mathrm{Km}$. The construction of the L7 span viaduct is on the old bridge across the Xinmin River, the construction site and layout of which is depicted in Figure X. The span of $\mathrm{L} 7$ viaduct is $89 \mathrm{~m}$, which is made up by a viable cross-section steel box girder with a total weight of 2200 tonne. The radius of sbg in vertical plane is $750 \mathrm{~m}$ with the difference of height change from $2.6 \mathrm{~m}$ to $3.8 \mathrm{~m}$.
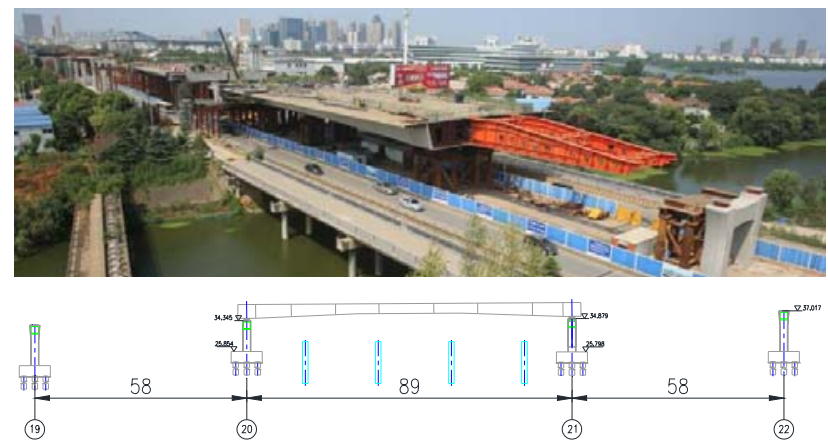

FIGURE IX. THE CONSTRUCTION SITE AND GENERAL LAYOUT OF DONGFENG AVENUE FREEWAY VIADUCT L7
Further, comparing to IL devices, the local structure stiffness of sbg is relatively low. Thus, to ensure the quality and safety of the launching construction, the relationship between the force and displacement is carefully controlled during each launching sequence. The reaction forces at all construction platforms which include assembly platform, \#1\#4 temporary piers are shown in Figure XI. The pushing distance is designed to be $300 \mathrm{~mm}$ in each iterated launching sequence. The lifting distance is controlled to be $150 \mathrm{~mm}$, at which the local launching interfaces of sbg is lifting away to the supporters. The rigid movement of sbg is monitored by the total station which is assembled on the top of the sbg with the precision of $10 \mathrm{mu}$ to better monitor and control the launching position and orientation.

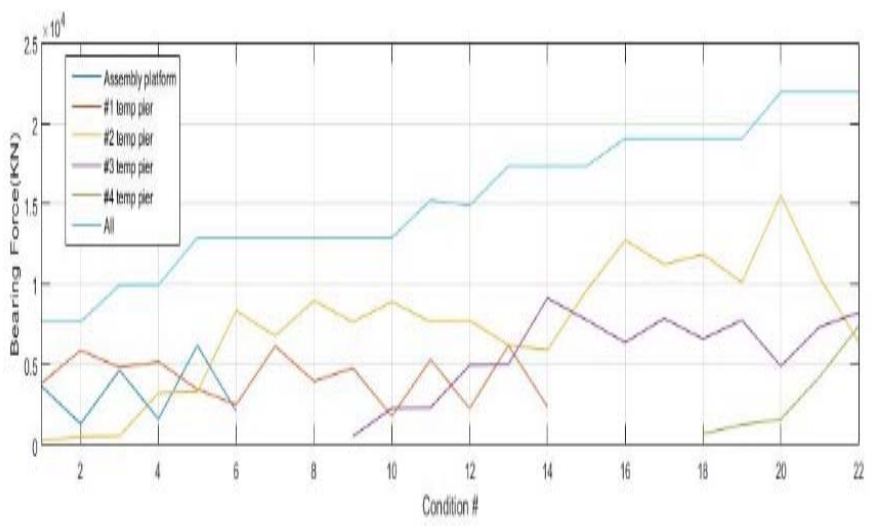

FIGURE X. THE BEARING FORCE AT ALL CONSTRUCTION PLATFORMS
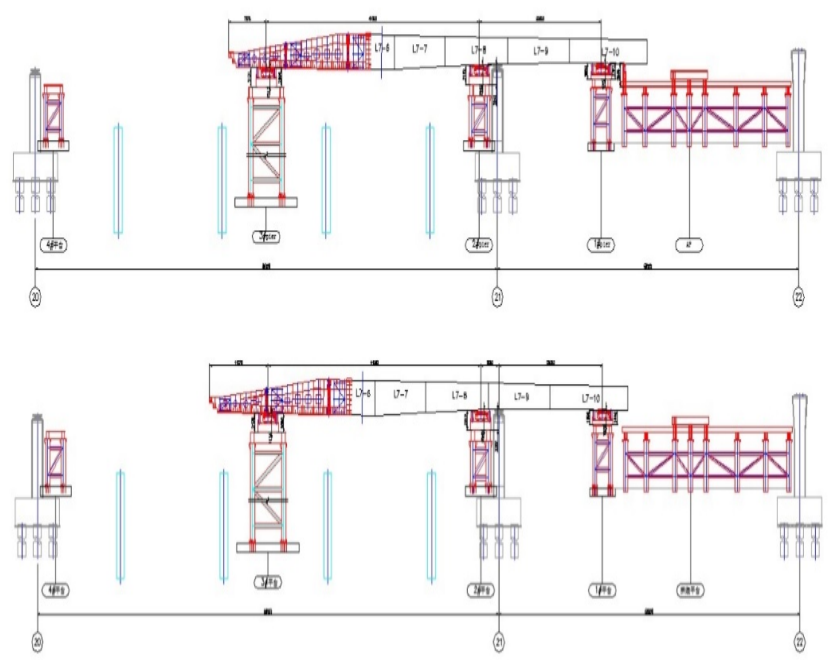

FIGURE XI. THE CONDITION 4 AND CONDITION 5 OF THE LAUNCHING CONSTRUCTION

The IL devices are self-adapt to the local curve feature of sbg in terms of its capability of 6-DoF movements, cusion layer and the height adjustment cylinders. There are total 22 launching sequences. Condition 4 and condition 5 , in which the L7-10 of sbg is started to be launched, are descirbed in Figure XII for sampling. The overall accuray of the 
construction bridge shape is within $5 \mathrm{~mm}$, and the synchronous movements errors of multi-point on-site IL devices is less than $1 \mathrm{~mm}$, which are shown in Figure XIII.

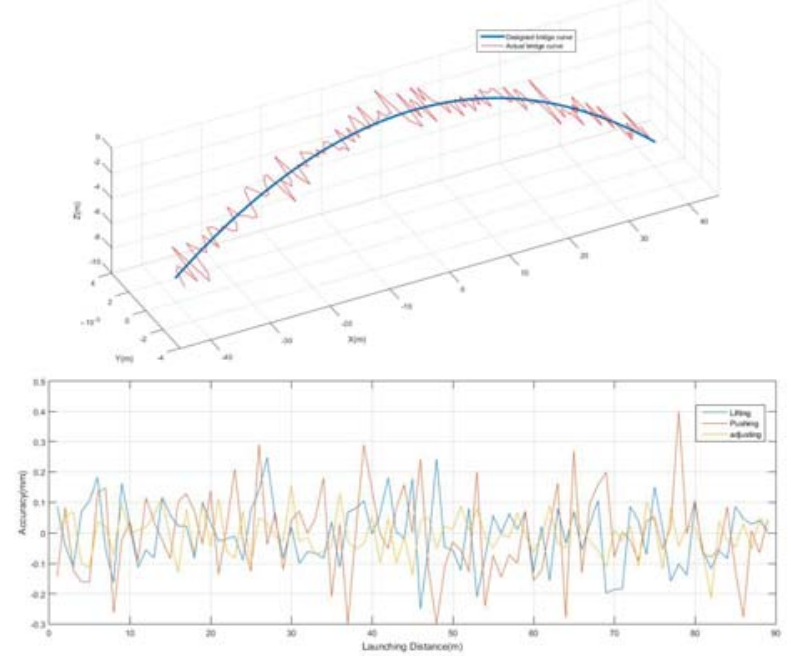

FIGURE XII. THE ACCURACY OF THE CONSTRUCTION BRIDGE SHAPE AND SYNCHRONOUS LAUNCHING MOVEMENTS

\section{CONCLUSION}

An new machatronic design of self-adptive incremental launching deivces was proposed in this paper. Firstly, the 6DoF mechanical structures and launching construction method of the device is introduced. In addition, the 70Mpa 1600 tonne hydaulic system and its transmission functions are discribed. Further, according to the mechanical movements of IL devices and the fine tunning functional requirments of hydaulic system, a distributed modular electrical control platform is particularly designed and integrated. Then, the construction application in Dongfeng Avenue freeway L7 89m viaduct is described. The multi-point synchronous launching accruracy is less than $1 \mathrm{~mm}$, and the precision of the bridge shape is within $5 \mathrm{~mm}$.

\section{ACKNOWLEDGMENT}

This work is supported by research and development projects of CCCC Second Harbor Engineering Company Ltd., which are "Special equipment Intelligent Monitoring System" and "The Visual Pose Control System of Incremental Launching Devices". Also, the authors would like to thank the Sixth Subsidiary of CCCC Second Harbor Engineering Company Ltd., and its engineers for their kind help and advice on launching construction.

\section{REFERENCE}

[1] B. Jacques, "Design development of steel-concrete composite bridges in France,' J. Constr. Steel Res. vol. 55(1-3), pp. 229-243, 2000

[2] H. Huang, L. Zhang, Z. Tian, "Analysis of secondary internal force for oblique continuous beam in the process of incremental launching," J. GZ univ. Nat. \& Sci. vol. 27(3), pp. 126-129, 2010

[3] R. June, U. Heymel, K.H. Reintjes, O. Schreiber, "Application of prefabricated sections for composite bridges shown on the example of Bahretal Bridge," Stahlbau. Vol. 78(6), pp. 385-393, 2009
[4] J.F. Wang, J.P. Lin, R.Q. Xu, "Incremental launching construction control of long multispan composite bridges," ASCE. J. Bridge Eng. Vol. 1084-0702. 04015006, pp. 1-9, 2015

[5] B. Kisch, P. Langefors, "Incremental launching versus Scaffolding for construction of Prestressed concrete bridges," Mast. Thesis. Chalmers Univ. of Technol, 2005

[6] M. Rosignoli, "Self-launching erection machines for precast concrete bridges,” J. PCI. Vol. 55(1), pp. 36-57, 2010

[7] K. Jung, K. Kim, C. Sim, J. Kim, "Verification of incremental launching construction safety for the ilsun bridge, the world's longest and widest prestressed concrete box girder with corrugated steel web section," J. Bridge. Eng. Vol. 16(3), pp. 453-460, 2011

[8] R. Marco, "Bridge Launching," Thomas Telford, London, 2002

[9] C.Y. Shao, "Key technological study of long span continuous composite box girder bridges," PhD. Thesis. Tongji Univ, 2007

[10] W. Zellner, H. Svensson, "Incremental Launching of structures," ASCE. J. Struct. Eng. Vol. 0733-9445. 109:2, pp. 520-537, 1983

[11] A. N. Fontan, J. M. Diaz, A. Baldomir and S. Hernandez, "Improved optimization formulations for launching nose of incrementally launched prestressed concrete bridges," ASCE. J. Bridge Eng. Vol. 1943-5592. 000016916, pp. 461-470, 2011

[12] M. Virlogeux, "The viaduct over the Tarn valley near Millau-from early design to completion," Bautechnik. Vol. 83(2), pp. 85-107, 2006

[13] M. Buonomo, C. Servant, M. Virlogeux, J. Cremer, V. de Ville De Goyet and J. D. Forno, "The design and the construction of the Millau Viaduct," J. Steelbridge. Millau, France, pp. 165-182.

[14] International Database for Civil and structural Engineering, http://structurae.net/structures/millau-viaduct

[15] F.G. Michele, "Analysis of non-uniform torsion in curved incrementally launched bridges,” J. Eng. Str. Vol. 75, pp. 374-387, 2014

[16] Z. H. Zhang, J. Y. Zhang, W. S. Hao, J. G. Dai and Y. Shen, "Hangzhou Jiangdong Bridge designed as a spatial self-anchored suspension bridge," J. Struct. Eng. Int. vol. 20(3), pp. 303-307, 2010

[17] Y.M. Bian, J. Jiang, B.X. Han, A.H. Li, G.J. Liu, "Design and Application of Hydraulic-Walking incremental Launching equipment," J. the open Constr. Build. Technol. Vol. 7(1), pp. 1-7, 2013

[18] M. LaViolette, T. Wipf, T. Lee, J. Bigelow, B. Phares, "Bridge construction practices using incremental launching," Bridge Eng. Center for Trans. Res. Edu. Iowa State University Ames: Iowa, vol. 50011, 2007 